\title{
Testing a novel method to identify salt production pottery via release and detection of chloride ions
}

\section{Citation}

Raad, Danielle R., Shuicheng Li, and Rowan K. Flad. 2014. "Testing a Novel Method to Identify Salt Production Pottery via Release and Detection of Chloride Ions." Journal of Archaeological Science 43 (March): 186-191. doi:10.1016/j.jas.2014.01.004.

\section{Published Version}

doi:10.1016/j.jas.2014.01.004

\section{Permanent link}

http://nrs.harvard.edu/urn-3:HUL.InstRepos:25220134

\section{Terms of Use}

This article was downloaded from Harvard University's DASH repository, and is made available under the terms and conditions applicable to Open Access Policy Articles, as set forth at http:// nrs.harvard.edu/urn-3:HUL.InstRepos:dash.current.terms-of-use\#OAP

\section{Share Your Story}

The Harvard community has made this article openly available.

Please share how this access benefits you. Submit a story.

\section{Accessibility}




\title{
Testing a novel method to identify salt production pottery via release and detection of chloride ions
}

\author{
Danielle R. Raad ${ }^{\mathrm{a}, 1, *}$, Li Shuicheng ${ }^{\mathrm{b}}$, Rowan K. Flad ${ }^{\mathrm{c}}$ \\ ${ }^{a}$ Department of Chemistry and Chemical Biology, Harvard University, Cambridge, MA \\ 02138 \\ ${ }^{b}$ School of Archaeology and Museology, Peking University, Beijing 100871, P.R. China \\ ${ }^{c}$ Department of Anthropology, Harvard University, Cambridge, MA 02138
}

\begin{abstract}
A recently published analytical technique to detect chloride ions in ceramic vessels that were used to produce salt is replicated (Horiuchi et al. 2011). The method involves releasing bound chloride ions permanently retained by the vessel via a chemical exchange reaction with ammonium fluoride, following the removal of all unbound salt with water. The chloride concentration is measured in solution and used to quantify the amount of salt that was bound to the ceramic matrix. Our data suggest that this method is not a viable way to consistently discriminate salt-making pottery, as the detected chloride may not be derived from salt production activities, but from the ceramic material of the pot itself. We employ experimental vessels in which salt-making was simulated, in addition to analyzing excavated sherds from two Chinese and one North American site known to have been involved in salt production. The method proposed by Horiuchi et al. is not able to distinguish salt-making and non-salt-making vessels from one another.
\end{abstract}

Keywords:

Salt, Salt-making pottery, Simulated pottery, Chinese ceramics, North American ceramics, Chloride, Ion-selective electrode

\footnotetext{
${ }^{*}$ Corresponding author

Email address: raad@mit.edu (Danielle R. Raad)

${ }^{1}$ Current Address: Center for Materials Research in Archaelogy and Ethnology, Department of Materials Science and Engineering, Massachusetts Institute of Technology, Cambridge, MA 02139
} 


\section{Introduction}

There is currently no low-cost method to unambiguously identify salt production pottery. The technique proposed by Horiuchi et al. (2011) promised to allow for the inexpensive chemical detection of salt within salt-making vessels, and would have had great potential to impact work on the archaeology of salt production worldwide. This study replicated this method using experimental pots and sherds from archaeological sites different from those of the original experiments.

One of us (RKF) was involved in the investigation of a specialized salt production site named Zhongba along the Yangzi River in the Three Gorges region of China (Flad 2011). Various aspects of the salt production taking place at the site were investigated, including an attempt to chemically verify that certain vessels were primarily used in the process of salt making (Flad et al. 2005). However, studies employing scanning electron microscopy (SEM) to examine concentrations of sodium $\left(\mathrm{Na}^{+}\right)$and chloride $\left(\mathrm{Cl}^{-}\right)$through crosssections of pottery have proven equivocal and unreliable. Furthermore, it is an expensive technique and requires highly skilled analysis.

\section{(Insert Figure 1)}

Horiuchi and colleagues proposed a method to retrieve water-insoluble chloride ions trapped within pottery matrices through the use of a relatively inexpensive chloride probe. They created ceramics that were similar to vessel types in antiquity, used them to make salt, and subsequently washed them with distilled water to mimic the removal of chloride by natural percolation after use. Their analysis showed that an ammonium fluoride solution was able to extract the trapped chloride ions from this experimental sample, via an anion exchange reaction (Fig. 1). They then tested the approach using excavated ceramics from several Japanese sites, and showed that the concentration of the trapped chloride ions was higher, in all cases, in ceramics thought to have been used for salt production relative to those that were not.

We replicated the experiment of Horiuchi et al. (2011) in a straightforward manner, using a variety of different material. We simulated salt making in experimental vessels, and employed archaeological samples both associated and unassociated with salt production. We analyzed sherds from Zhongba, from the recently excavated site of Shuangwangcheng in Shandong Province, China (Li et al. 2009), and from Kimmswick, Missouri, a prehistoric saline 
site curated in the Peabody Museum of Archaeology and Ethnology at Harvard. We hoped to verify this method and thus further extend previous research on salt production at these sites and, in the case of Zhongba, expand on the limited but provocative chemical work done previously by comparing ceramics thought to have been used for salt making to those that were thought to be used for other purposes.

\section{Experimental}

\subsection{Materials}

Four sets of material were analyzed in this study in order to evaluate the claims made by Horiuchi and associates (2011) that chloride ions exchange with anions in pottery during the process of salt pan formation and can be thus chemically released and detected. These include experimental vessels in which salt making was simulated, sherds from two sites in China and one in North America where salt production activities have been identified. A total of forty-two samples were analyzed, twenty-eight of which are known, based on context and typology, to have been used in salt production, seven that are known to have not been used in salt production, and seven of unconfirmed function.

Three terra cotta vessels were donated by the Harvard Ceramics Program. Two experimental pots were filled with a brine solution made up of tap water saturated with salt and heated on a stove. Salt pan was left behind as the water evaporated, simulating the salt extraction process from sea water. One pot (E2) went through a single cycle of being filled with salt water and reduced down to a solid salt pan. Additional brine was continuously added to the other pot (E1) until the bottom cracked and the vessel was no longer able to carry water. The entire exterior of the pot was caked in salt, which travels through a porous ceramic body during evaporation. Samples from the rim (E1R, E2R), body (E1M, E2M), and base (E1B, E2B) were separately analyzed for the two experimental vessels used to make salt pan. A third experimental pot (E3) was never put into contact with salt and served as a control.

The second group of sampled material included sixteen sherds from the site of Shuangwangcheng in Shandong Province, China (SI Fig. C.1; Cao 1996; Cui 2011; Li et al. 2003, 2009; Peng 2012; Shandong and Shandong 2012; Shandong et al. 2010a, 2010b). Eleven of these (S1-11) are known to have been used to produce salt and include both rim and body sherds, orange 
and grey ceramic materials, and lightly to heavily rope-corded exterior surface textures (SI Table A.1). Two sherds from Shuangwangcheng (S12, S14) are known to have not been used to produce salt while the three remaining sherds (S13, S15-16) were most likely unassociated with salt production.

The third group of ceramics was made up of ten sherds from the site of Zhongba in the Three Gorges Region of China (SI Fig. C.2; Chen 2008; Flad 2007, 2011; Sichuan and Chongqing n.d.; Sun 2003), eight of which are portions of vessels known to have been involved in salt production, including the rims of storage vats and conical cups (Z1-6, Z9-10). One conical cup was potentially used to hold salt (Z7), while another rim sherd was definitely not involved in salt production (Z8).

The fourth set of sherds came from the Mississippian site of Kimmswick, Missouri, and was provided for this study by the Peabody Museum of Archaeology and Ethnology at Harvard University (SI Fig. C.3; Bushnell 1907, 1908). A total of nine sherds included three used in salt production (K7$9)$, three that were not (K1, K5-6), and three that were found near a salt spring but were not necessarily associated with salt production (K2-4; SI Table A.1).

\subsection{Extraction of Unbound Chloride}

The first step of the Horiuchi method requires all unbound, water-soluble chloride to be completely removed from each sample. All visible dirt was washed off of the sherds by hand in a sink. Next, each sherd was sonicated in a beaker of distilled water, to mimic post-depositional removal of soluble chloride through the surface. Using a rock cutting saw, 6-10g pieces of each sherd were removed; in the case of the smallest sherds (S6, S16), the entire sample was used. In the case of the Mississippian ceramics from Kimmswick, samples were removed before any dirt was cleaned off, in order to preserve the original soil on the sherds so that they may be returned to the Peabody museum as unaltered as possible. The removed pieces were then rinsed off and sonicated in distilled water. Once thoroughly washed, each sample was cut into small cubes and left in a desiccating vacuum chamber overnight to completely dry. These were then powderized in either a rock crusher or a shatterbox.

Three $1.00 \mathrm{~g}$ portions of powdered sherds were placed in three separate $50 \mathrm{~mL}$ centrifuge tubes (every measurement was taken in triplicate, and the data points are reported here as averages plus or minus one standard deviation). Once the powdered sherds were measured into centrifuge tubes, $10 \mathrm{~mL}$ 
of distilled water was added via pipet. These were next sonicated for 10 minutes, then centrifuged at 300rpm for five minutes. The clear supernatant was poured into a new centrifuge tube containing $1 \mathrm{~mL}$ of ionic strength adjustor (ISA). The chloride concentration of this solution was measured with a SympHony Chloride Ion Selective Combination Electrode (VWR International), calibrated using standard solutions of 10,100, and 1000ppm $\mathrm{Cl}^{-}$.

An additional $10 \mathrm{~mL}$ of distilled water was added to the centrifuge tube containing the pellet of powdered sherds, and the procedure was repeated through a total of one to four additional cycles of sonication, centrifugation, and measurement until the chloride concentration dropped below the limit of detection (<LOD; 1.8ppm) of the probe (Fig. 4a; Extractions 1-5). To confirm the necessity of using distilled, or de-ionized (DI) water, the chloride concentration of tap water and distilled water were measured and found to be $200 \mathrm{ppm}$ and below the limit of detection, respectively.

\subsection{Extraction of Bound Chloride}

Once all unbound chloride was removed from the powdered sherds via repeated washings with distilled water, a second round of extractions with ammonium fluoride $\left(\mathrm{NH}_{4} \mathrm{~F}\right)$ was carried out in order to release the bound chloride permanently installed in the ceramic matrix. A stock solution of $0.25 \mathrm{M} \mathrm{NH}_{4} \mathrm{~F}$ (98+\% purity, Sigma Aldrich) in distilled water was prepared. The chloride concentration of this solution was confirmed to be below the limit of detection of the probe. The same cycle of sonication, centrifugation, and measurement was repeated, this time with the $0.25 \mathrm{M} \mathrm{NH}_{4} \mathrm{~F}$ solution instead of distilled water, until either the chloride concentration dropped below the limit of detection of the probe, or eight cycles were completed (Fig. 4; Extractions 6-13).

Horiuchi et al. (2011) tested aqueous ammonium fluoride solutions of $0.028,0.056$, and $0.28 \mathrm{M}$, and determined $0.28 \mathrm{M}$ to be the most suitable concentration. In this study, we accordingly employed a solution of $0.25 \mathrm{M}$ $\mathrm{NH}_{4} \mathrm{~F}$, approximately equal to their concentration yet more mathematically round.

\subsection{Scanning Electron Microscopy}

Scanning electron microscopy with energy-dispersive X-ray spectroscopy (SEM-EDS) analyses were carried out on cross-sections of samples that were thoroughly washed and sonicated with de-ionized water. The sectioned sherds were examined with a Tescan Vega III scanning electron microscope 
equipped with a Bruker X-Flash 5030 energy dispersive spectrometer. The backscattered SEM images and the EDS spectra and maps were acquired at an accelerator voltage of $20 \mathrm{kV}$ and a working distance of $16 \mathrm{~mm}$ (40kcps and $3 \%$ detector dead time for the spectra and $4 \mathrm{kcps}$ and $15 \%$ dead time for the maps). All EDS spectra and maps were collected from areas measuring $1.5 \mathrm{~mm} \times 1.5 \mathrm{~mm}$.

\author{
(Insert Figure 2) \\ (Insert Figure 3) \\ (Insert Table 1)
}

\title{
3. Results and Discussion
}

The first stage in the analysis was the removal of any unbound chloride. This is necessary for two potential reasons: (a) salt may have been introduced into the ceramic matrix postdepositionally, and is therefore unrelated to the function of the vessel and must be removed, or (b) salt actually introduced into the ceramic during salt production that remains soluble may be removed during burial in the ground and is thus an inconsistent and unreliable marker. Consequently, only the bound chloride extracted by the exchange reaction with fluoride would potentially be able to display meaningful trends.

After all of the unbound chloride was removed by repeated washings with water and the measured concentration of chloride falls below the limit of detection of the probe, ammonium fluoride was employed in subsequent cycles (Fig. 4). Fluoride exchanged with chloride permanently bound in the ceramic matrix, releasing it into solution and causing the measured amount of chloride to significantly increase. Thus, we see a spike in chloride concentration once an ammonium fluoride solution is used instead of water (between extractions 5 and 6 in Fig. 4a). Horiuchi et al. observed this trend, but only significantly for samples that had been used in salt production. They argue that the total amount of bound chloride extracted by ammonium fluoride (the sum of each individual extraction, given in units of $\mathrm{mg} \mathrm{Cl}^{-}$per g pottery) may be used as a marker for salt production. Our data, however, do not show this distinction.

Tabulated results of the total amount of chloride recovered from extractions with water and with ammonium fluoride are given in Table 1. Vessels known to have been used in salt production do not generally release more 
bound chloride than vessels known to have not been used in salt production. This is highlighted in Figures 2 and 3, which show the average amount of chloride extracted from salt and non-salt ceramics at each site.

(Insert Figure 4)

\subsection{Analysis of Experimental Vessels}

For the experimental vessels in which salt production was simulated, we see a direct correlation between contact with salt and the concentration of unbound chloride in the ceramic matrix (Table 1; SI Table B.2). The most unbound chloride was extracted and measured in solution from all samples taken from the pot that was used to make salt pan until vessel failure (E1; $\sim 10 \mathrm{mg} \mathrm{Cl}^{-} / \mathrm{g}$ pottery). Slightly less salt was recovered from the samples of the pot that was put through only one cycle of salt water evaporation (E2; 6-7mg Cl-/g pottery), though significantly more than the amount of unbound chloride recovered from the control pot (E3; $0.03 \mathrm{mg} \mathrm{Cl}^{-} / \mathrm{g}$ pottery). Although these trends correspond well with the function of the pot, chloride that may be removed by dissolution in water (unbound chloride) would not be a reliable marker for salt production for the two reasons that have been described above.

The total chloride extracted by the solution of ammonium fluoride did not mimic the trend seen above. The amount of bound chloride removed from the pot that was never put into contact with salt (E3) lies within the range of observed values for the amount of chloride extracted from the simulated salt production vessels (Figs. 3, 4b). Our experimental control indicates that bound chloride is not be a dependable proxy for salt making.

Furthermore, there is a trend for both of the experimental salt production vessels (E1 and E2) concerning bound chloride extracted from different locations. Samples from the rim (E1R and E1R), body (E1M and E2M), and base (E1B and E2B) were taken from each of the two terra cotta pots. For each vessel, rim sherds produced significanly more bound chloride than body sherds, while the base sherds produced the least. This contrasts with the results of Horiuchi et al. (2011), who reported a higher concentration of salt in body sherds.

\subsection{Analysis of Shuangwangcheng Ceramics}

The trends observed in the amount of chloride extracted from the sherds from Shuangwangcheng are even less correlated (Table 1; SI Tables B.3, B.4). 
The amount of unbound chloride recovered from washing with water seems unrelated to whether or not the original vessel facilitated salt production, which is to be expected from sherds excavated from the complex saline environment of the ground. In addition, the total amount of chloride recovered from extractions with ammonium fluoride does not parallel the function of the vessel. Interestingly, one body sample known to have not been used to produce salt (S14; 1.013mg Cl${ }^{-} / \mathrm{g}$ pottery; Table 1, Fig.4) produced almost double the amount of chloride as the known salt-making vessel with the greatest saline content (S6; $0.567 \mathrm{mg} \mathrm{Cl}^{-} / \mathrm{g}$ pottery). On average, more salt was extracted from non-salt production pottery (Figs. 2, 3), a trend that can still be seen even if the four rim (S1, S4, S8 and S9) and one base (S12) sherds are excluded from the Shuangwangcheng data set.

\subsection{Analysis of Zhongba Ceramics}

This lack of a trend is again observed in the samples from Zhongba (Table 1; SI Table B.5). This set of material produced almost no unbound chloride, perhaps indicating some sort of postdepositional environment that drew out the mobile saline content of the sherds. Once again, the sample in this set that released the greatest amount of bound chloride is from a vessel known typologically to not have been used in salt production (Z8). As with the samples from Shuangwangcheng, more salt was extracted on average from the Zhongba sherds not associated with salt production that those that were.

\subsection{Analysis of Kimmswick Ceramics}

The ranges of chloride extracted from salt and non-salt production sherds at Kimmswick, MO overlap as well, regardless of whether rim and body samples are considered separately or together (Table 1; SI Table B.6). Three sherds found near the salt spring, unassociated with salt production activities, yielded the greatest amount of extracted chloride (although the amount of detected unbound chloride was not correlated in this way). It is clear that it would not be possible to classify the unknown sherds based on this method (Fig. 3). The total amount of bound chloride extracted from the samples from Kimmswick were, in all cases, significantly (one order of magnitude) greater than the salt extracted from the experimental and two archaeological Chinese samples (Fig. 2). 


\subsection{Results from SEM-EDS Analysis}

To provide a separate line of evidence, scanning electron microscopy with energy-dispersive X-ray spectroscopy (SEM-EDS) was used to elementally characterize cross-sections of five salt production sherds (S3, S11, Z1, Z2, and Z6) and one non-salt associated sherd (S12). The amount of chlorine detected in the non-salt-production sample S12 (normalized weight percent relative to silicon and aluminum) was within the range of the other sherds. Chlorine was evenly distributed in all samples, with no gradients from interior to exterior of the sherd cross-sections (SI Figs. D4), contrasting with findings previously reported for salt production vessels from Zhongba (Flad et al. 2005). Our results are consistent with the macroscopic observation that salt passed completely through the porous ceramic during evaporation, accumulating on the exterior of the experimental vessel. Backscattered electron images and SEM-EDS elemental maps of sample Z1 (Fig. 5) highlights the extensively heterogeneous nature of these inclusion-rich vessels. Chlorine is not shown in this map due to its even distribution and consistently low concentration, contrasting with the discrete inclusions rich in sodium, silicon, potassium, and iron.

\section{(Insert Figure 5)}

\subsection{Comments on Sherd Location}

Out of the 42 sherds analyzed in this study, $50 \%$ are body sherds (21 samples), $40 \%$ are rim sherds (17 samples) and 10\% are base sherds (4 samples). Although most specimens originate from the body of the vessel, a large portion of are rim fragments. These rim sherds were chosen and supplied by our Chinese colleagues due to the relative ease by which they may be typologically identified, and confirmed as having been involved in salt production. In our experimental samples, we found that exracted chloride content did depend on salt sherd location, with rim sherds containing the most, and base sherds the least amount of chloride (Table 1; SI Table B.2).

We agree that sampling from the body of a vessel might eliminate extreme values and standardize the data (Horiuchi 2011). However, it is necessary to focus on visually identifiable and diagnostic sherds in order to comment on the viability of this technique. The observed lack of a trend differentiating salt production pottery from non-salt production pottery is detailed in this paper for a mix of body, rim, and base samples. However, these results are

consistent for locational subsets of the data, and hold true for an analysis of 
either just body or just rim sherds. The Horiuchi method may indeed be useful to distinguish salt production pottery from body sherds only, but support for such a claim is inhibited by the inability to confirm a significant amount of body sherds as involved in salt production via a typological alternate line of evidence.

\section{Conclusions}

Horiuchi et al. (2011) urge their experiments to be repeated with examples of pottery from other salt production sites made up of different ceramic materials and using different sources of saline water to make salt. This study reports such data from our own experimental specimens: two salt production sites in China and one near a salt spring in Kimmswick, Missouri.

Two rounds of extraction and measurement cycles were carried out in triplicate for each sample of powdered sherds. The first round, employing distilled water as the solvent, dissolved any soluble, or unbound, chloride in the samples, until the concentration of chloride released dropped below the limit of detection of the ion selective electrode. In the second round, a solution of ammonium fluoride was used instead, resulting in an exchange reaction between the fluoride and chloride, releasing chloride bound to the ceramic matrix into solution, where it may be detected (Fig. 1). This caused a noticeable jump in the concentration of chloride compared to the negligible amounts of the last cycle with distilled water (Fig. 4a). Horiuchi et al. see a difference in the total amount of chloride extracted in this second round between salt and non-salt production pottery, thus claiming that their method is a cost-effective way to distinguish between the two.

In our experiments, we see that chloride is indeed released upon extraction, but the origin is unlikely to be salt production. The same trend is observed for vessels known to have been involved in salt making and those that are not (Fig. 4). A potential source of bound chloride could be the material of the pot, either from inclusions or from the ceramic body itself, and not salt production activities. An analogous data set of sodium ion concentrations might serve to further substantiate these claims. It is interesting to note that the total bound chloride extracted from the Kimmswick sherds, all of which are shell-tempered, is an order of magnitude greater than the other samples. This seems to indicate that inclusions could be a likely source of the bound chlorine. We contend that the Horiuchi method is not a reliable way 
to consistently discriminate salt-making pottery. Unfortunately, this leaves us with no effective technique to do so.

\section{Acknowledgements}

This research was funded by a Collections Research Grant from the Peabody Museum of Archaeology and Ethnology at Harvard University. DRR was supported by an NSF Graduate Research Fellowship (GRFP). We would also like to thank Wei Chengmin (Shandong Provincial Institute of Archaeology), Sun Zhibin and Gao Dalun (Sichuan Provincial Institute of Archaeology), James Weaver (Wyss Institute, Harvard Universtiy), Shawn Panepinto (Harvard Ceramics Program), and Diana Loren and Genevieve Fisher (Peabody Museum).

\section{References}

\section{References}

[1] Bushnell, D.I. 1907. Primitive Salt-Making in the Mississippi Valley. Man 7(13): 17-21.

[2] Bushnell, D.I. 1908. Primitive Salt-making in the Mississippi Valley, II. Man 8(35): 65-70.

[3] Cao, Y. 1996. Shilun Xi Zhou zhi Zhanguo shidai de kuixingqi (Discussing the "helmet-shaped" vessels of the Western Zhou to Warring States period). Beifang wenwu [Relics from the North] 1996(3):26.

[4] Chen, P. 2008. Technical Changes in the Salt Production from the Neolithic Period to the Han Dynasty at Zhongba. Sel, eau et fort Dhier aujourdhui, ed. O. Weller, A. Dufraisse and P. Ptrequin. Paris, Presses universitaires de Franche-Comt: 143-161.

[5] Cui, J. 2011. Archaeometric research on the salt production site of Shuangwangcheng in Shouguang, Shandong. Nanfang wenwu [Relics from the south] 2011(1):116-119.

[6] Flad, R.K. 2007. Rethinking the Context of Production through an Archaeological Study of Ancient Salt Production in the Sichuan Basin, 
China. Rethinking Craft Specialization in Complex Societies: Archaeological Analyses of the Social Meaning of Production, ed. Z.X. Hruby and R.K. Flad. Berkeley, American Anthropological Association and the University of California Press:108-128.

[7] Flad, R.K. 2011. Salt Production and Social Hierarchy in Ancient China: An Archaeological Investigation of Specialization in Chinas Three Gorges, Cambridge University Press, Cambridge.

[8] Flad, R.K., J. Zhu, C. Wang, P. Chen, L. von Falkenhausen, Z. Sun, and S. Li. 2005. Archaeological and chemical evidence for early salt production in China. PNAS 102(34) 12618-12622.

[9] Horiuchi, A., N. Ochiai, H. Kurosumi, and Y. Miyata. 2011. Detection of chloride from pottery as a marker for salt: A new analytical method validated using simulated salt-making pottery and applied to Japanese ceramics. Journal of Archaeological Science 38:2949-2956.

[10] Li, S., L. Yufu, and W. Hui. 2009. Lu bei - Jiaodong yanye kaogu diaochaji (Report on the archaeological surveys of salt production in Northern Shandong to the Jiaodong Peninsula). Huaxia kaogu (Huaxia Archaeology) 1:11-25.

[11] Li, S., L. Yufu, H. Wang, and H. Mingming. 2003. Laizhouwan diqu gudai yanye kaogu diaocha A survey of ancient salt production archaeology in the Laizhou bay region). Yanyeshi yanjiu [Journal of Salt Industry History Research] 2003(1):82-91

[12] Peng, P. 2012. Lu bei Laizhouwan yanan Shangzhou Shiqi zhiyan gongyi chutan (Discussion of the tools used for making salt during the Shang and Zhou periods on the coast of the Laizhou Bay in northern Shandong). Nanfang wenwu [Relics from the south] 2012(1):53-58.

[13] Shandong Sheng Wenwu Kaogu Yanjiusuo and Shandong Changyi Shi Bowuguan. 2012. Shandong Changyi Shi yanye yizhi diaocha jianbao (Preliminary report on the survey of salt production sites in Changyi City, Shandong). Nanfang wenwu [Relics from the south] 2012(1):59-62.

[14] Shandong Daxue Kaoguxi, Shandong Sheng Wenwu Kaogu Yanjiusuo and Dongying Shi Lishi Bowuguan. 2010. The Western Zhou salt boil- 
ing site of Nanheya in Dongying City, Shandong. Kaogu [Archaeology] 2010(3): 39-47.

[15] Shandong Sheng Wenwu Kaogu Yanjiusuo, Beijing Daxue Zhongguo Kaoguxue Yanjiu Zhongxin and Shouguang Shi Wenwuju. 2010. The 2008 excavations at the salt production site of Shuangwangcheng in Shouguang City, Shandong. Kaogu [Archaeology] 2010(3):18-36.

[16] Sichuan Sheng Wenwu Kaogu Yanjiusuo and Chongqing Shi Zhong Xian Wenwu Baohu Guanlisuo. n.d. Zhong Xian Zhongba [Zhongba in Zhong County]. Beijing, Kexue chubanshe.

[17] Sun, Z. 2003. Zhongxian Zhongba yizhi de xingzhi - yanye shengchan de sikao yu tansuo (The Nature of the Zhongba Site in Zhong Xian County - Thoughts Concerning Salt Production). Yanyeshi yanjiu (Journal of Salt Industry History Research] 2003(1): 25-30. 
Figure 1: The Horiuchi mechanism. Fluoride ions exchange for the permanently bound chlorine in the ceramic, releasing chloride ions into solution and rendering them detectable. 


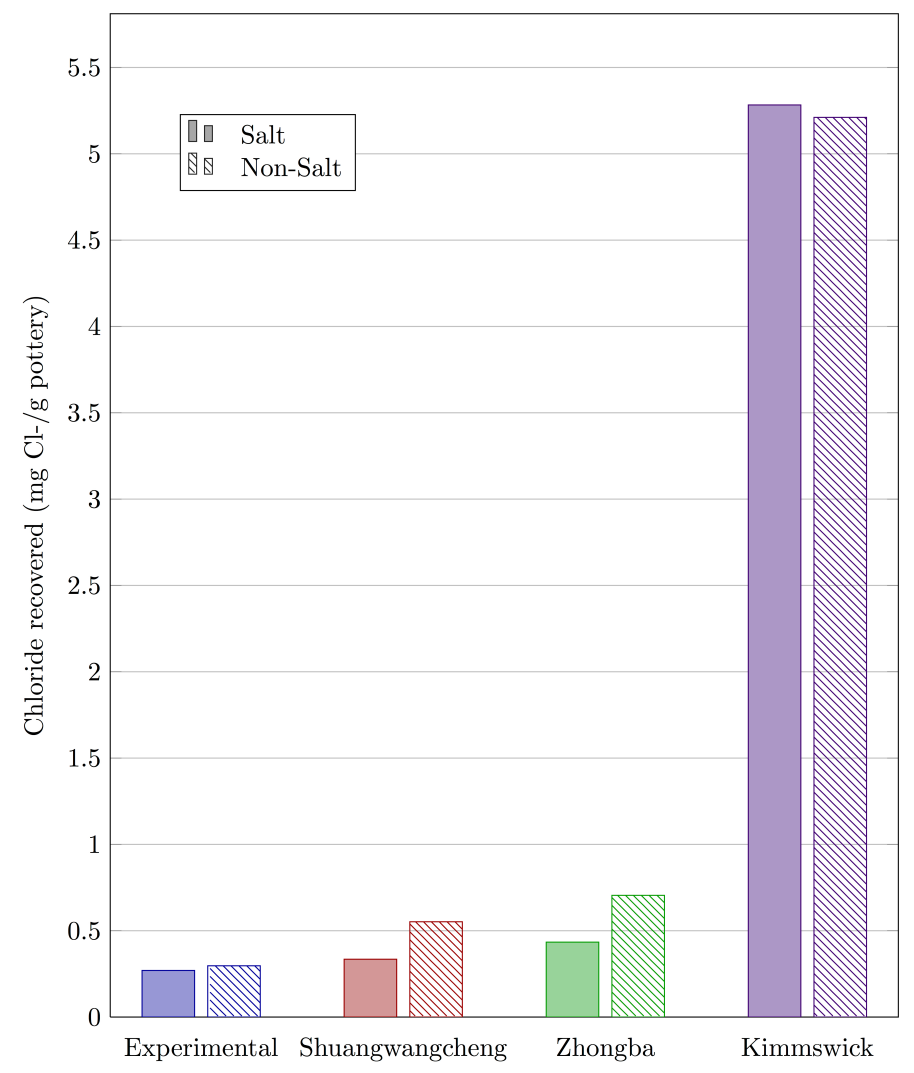

Figure 2: Average amount of bound chloride recovered from both salt (solid bars) and non-salt (hatched bars) sherds from the experimental vessels and the three archaeological sites in this study. Samples of unknown use have been excluded from this graph. 


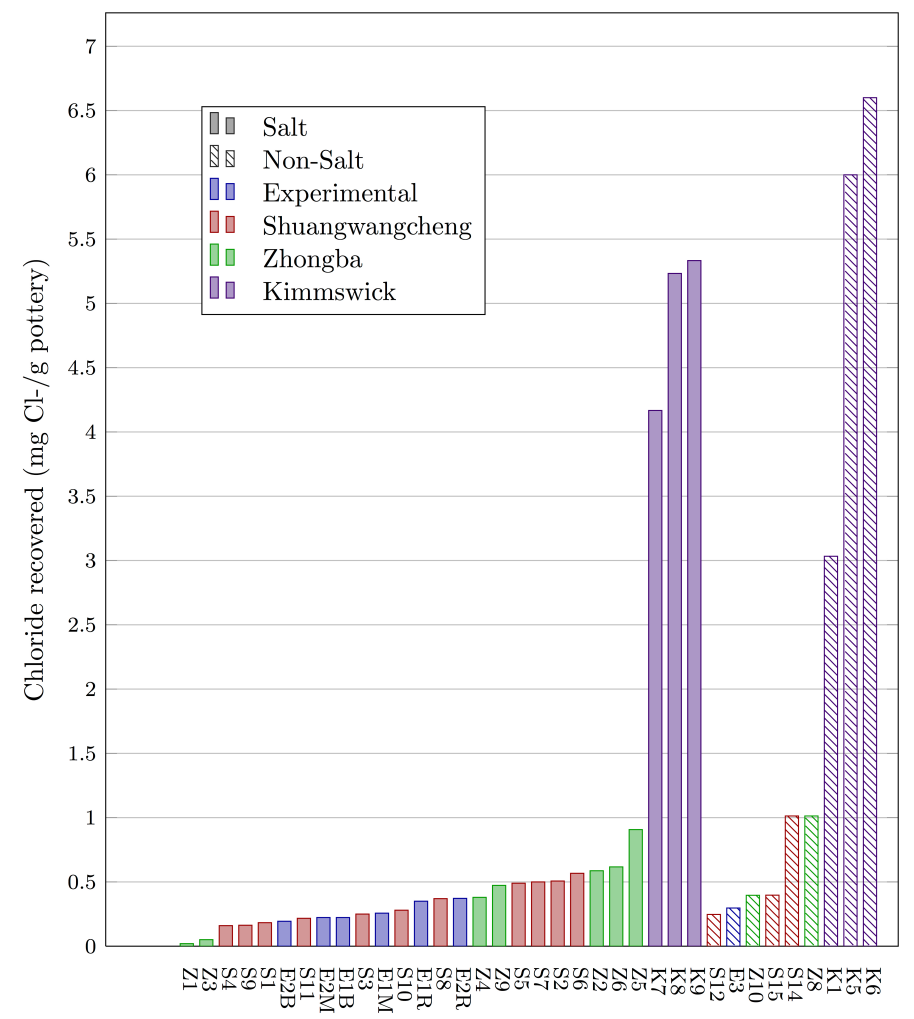

Figure 3: Total amount of bound chloride recovered from all of the salt (left; solid bars) and non-salt (right; hatched bars) sherds from the experimental vessels and the three archaeological sites in this study. Samples of unknown use have been excluded from this graph. 


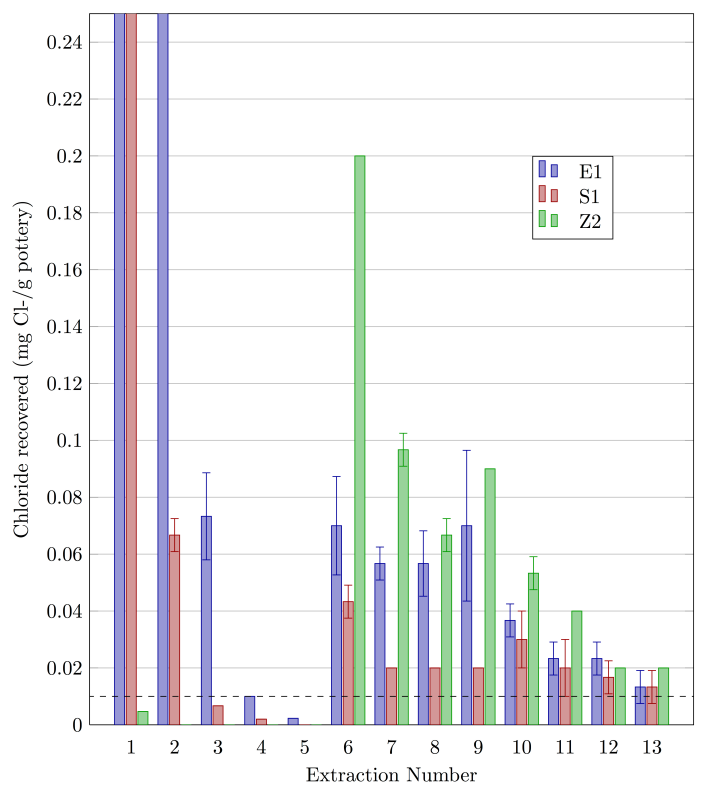

(a)

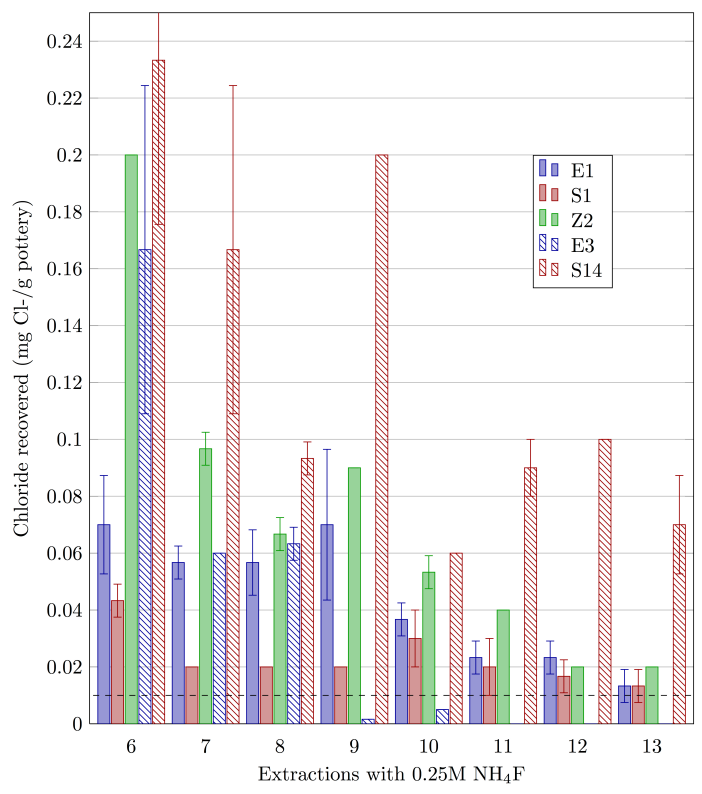

(b)

Figure 4: (a) Chloride recovered per extraction for three salt production sherds. Extractions 1-5 are with DI water, removing unbound chloride. Extractions 6-13 are with $0.25 \mathrm{M} \mathrm{NH}_{4} \mathrm{~F}$, removing the supposed permanently bound chloride. (b) Chloride recovered per extraction with $\mathrm{NH}_{4} \mathrm{~F}$ for salt as well as non-salt production potteng samples. Dotted line is the limit of detection. Error bars indicate one standard deviation from the average of three trials. 

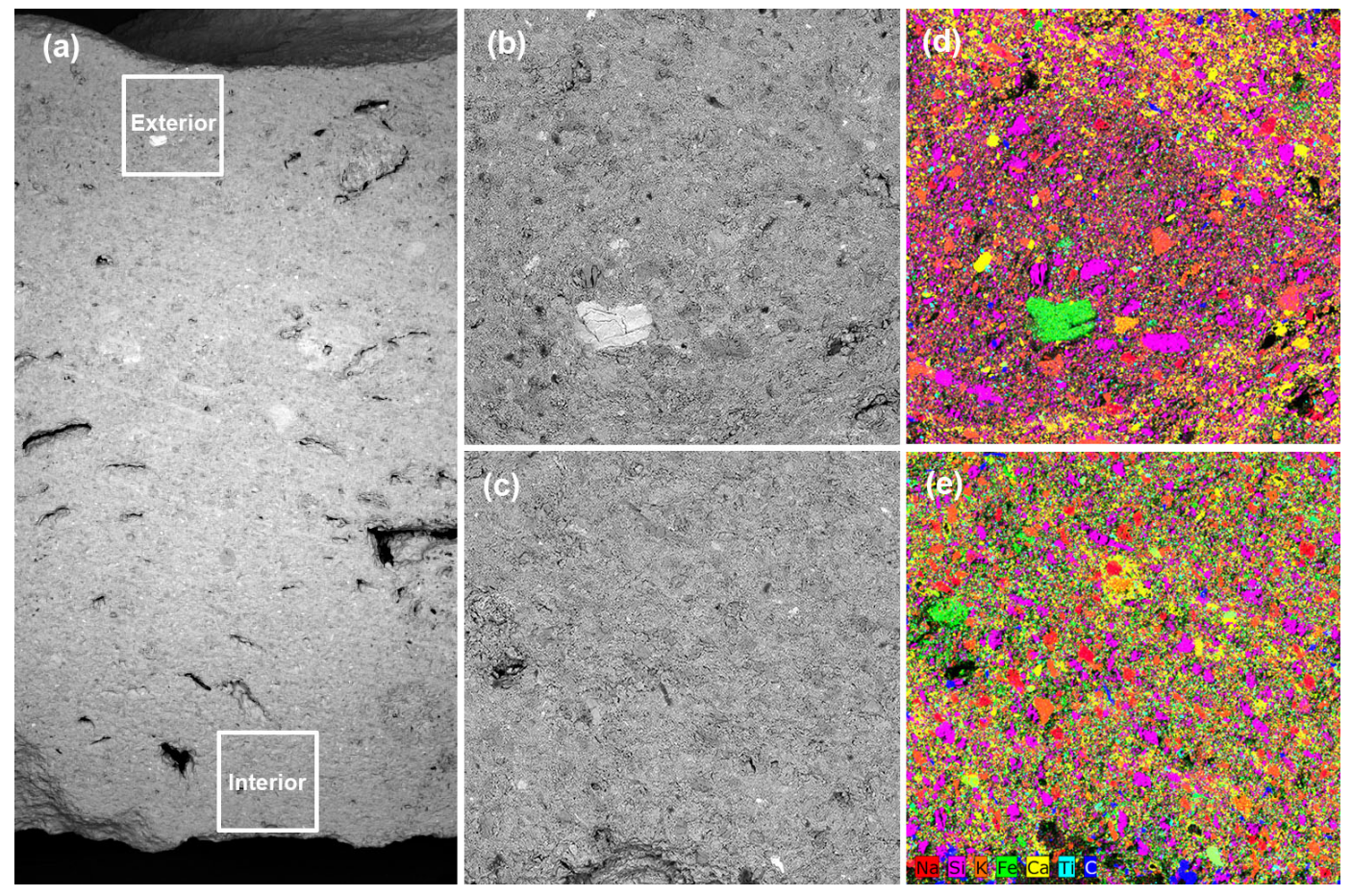

Figure 5: SEM backscattered electron images of (a) a cross-section of sample $\mathrm{S} 3$ and $1.5 \mathrm{~mm} \times 1.5 \mathrm{~mm}$ areas on the (b) exterior and (c) interior of the sample corresponding to the locations of the $(\mathrm{d})$ exterior and (e) interior SEM-EDS elemental maps depicting sodium (red), silicon (pink), potassium (orange), iron (geen), calcium (yellow), titanium (light blue), and carbon (dark blue). 


\begin{tabular}{|c|c|c|c|c|}
\hline Sample & $\begin{array}{c}\text { Total } \mathrm{Cl}^{-} \text {recovered } \\
\text { with distilled water } \\
(\mathrm{mg} / \mathrm{g} \text { pottery }) \\
\end{array}$ & $\begin{array}{c}\text { Total } \mathrm{Cl}^{-} \text {recovered } \\
\text { with } 0.25 \mathrm{M} \mathrm{NH}_{4} \\
(\mathrm{mg} / \mathrm{g} \text { pottery }) \\
\end{array}$ & Salt? & Location \\
\hline E1R & $10.852 \pm 0.052$ & $0.350 \pm 0.013$ & $\mathrm{Y}$ & $\operatorname{Rim}$ \\
\hline E1M & $10.875 \pm 0.045$ & $0.257 \pm 0.011$ & $\mathrm{Y}$ & Body \\
\hline E1B & $10.068 \pm 0.521$ & $0.223 \pm 0.011$ & $\mathrm{Y}$ & Base \\
\hline E2R & $6.583 \pm 0.029$ & $0.372 \pm 0.005$ & $\mathrm{Y}$ & $\operatorname{Rim}$ \\
\hline E2M & $6.143 \pm 0.290$ & $0.223 \pm 0.026$ & $\mathrm{Y}$ & Body \\
\hline E2B & $7.727 \pm 0.061$ & $0.194 \pm 0.005$ & Y & Base \\
\hline E3 & $0.033 \pm 0.003$ & $0.297 \pm 0.026$ & $\mathrm{~N}$ & Body \\
\hline S1 & $1.075 \pm 0.003$ & $0.183 \pm 0.006$ & $\mathrm{Y}$ & $\operatorname{Rim}$ \\
\hline S2 & $0.649 \pm 0.001$ & $0.507 \pm 0.009$ & Y & Body \\
\hline S3 & $0.702 \pm 0.026$ & $0.250 \pm 0.007$ & $\mathrm{Y}$ & Body \\
\hline S4 & $0.552 \pm 0.003$ & $0.160 \pm 0.009$ & $\mathrm{Y}$ & $\operatorname{Rim}$ \\
\hline S5 & $3.209 \pm 0.026$ & $0.490 \pm 0.015$ & $\mathrm{Y}$ & Body \\
\hline S6 & $2.143 \pm 0.003$ & $0.567 \pm 0.026$ & $\mathrm{Y}$ & Body \\
\hline S7 & $2.236 \pm 0.003$ & $0.500 \pm 0.012$ & $\mathrm{Y}$ & Body \\
\hline S8 & $1.145 \pm 0.029$ & $0.370 \pm 0.008$ & $\mathrm{Y}$ & $\operatorname{Rim}$ \\
\hline S9 & $1.520 \pm 0.290$ & $0.163 \pm 0.004$ & $\mathrm{Y}$ & Rim \\
\hline S10 & $0.594 \pm 0.029$ & $0.280 \pm 0.006$ & $\mathrm{Y}$ & Body \\
\hline S11 & $0.263 \pm 0.029$ & $0.217 \pm 0.004$ & $\mathrm{Y}$ & Body \\
\hline S12 & $0.217 \pm 0.006$ & $0.247 \pm 0.006$ & $\mathrm{~N}$ & Base \\
\hline S13 & $0.364 \pm 0.029$ & $0.270 \pm 0.008$ & $\mathrm{~N} ?$ & Body \\
\hline S14 & $1.097 \pm 0.005$ & $1.013 \pm 0.030$ & $\mathrm{~N}$ & Body \\
\hline S15 & $0.554 \pm 0.185$ & $0.970 \pm 0.036$ & $\mathrm{~N} ?$ & Body \\
\hline S16 & $0.612 \pm 0.029$ & $0.397 \pm 0.005$ & $\mathrm{~N} ?$ & Body \\
\hline $\mathbf{Z 1}$ & $0.000 \pm 0.000$ & $0.020 \pm 0.000$ & $\mathrm{Y}$ & Rim \\
\hline $\mathrm{Z2}$ & $0.005 \pm 0.002$ & $0.587 \pm 0.004$ & $\mathrm{Y}$ & $\operatorname{Rim}$ \\
\hline Z3 & $0.000 \pm 0.000$ & $0.051 \pm 0.005$ & $\mathrm{Y}$ & Rim \\
\hline $\mathrm{Z} 4$ & $0.057 \pm 0.004$ & $0.380 \pm 0.005$ & $\mathrm{Y}$ & Base \\
\hline $\mathrm{Z5}$ & $0.008 \pm 0.002$ & $0.907 \pm 0.022$ & $\mathrm{Y}$ & $\operatorname{Rim}$ \\
\hline $\mathrm{Z} 6$ & $0.000 \pm 0.000$ & $0.617 \pm 0.022$ & $\mathrm{Y}$ & Body \\
\hline $\mathrm{Z7}$ & $0.000 \pm 0.000$ & $0.073 \pm 0.002$ & $\mathrm{Y} ?$ & Body \\
\hline $\mathrm{Z8}$ & $0.000 \pm 0.000$ & $1.013 \pm 0.006$ & $\mathrm{~N}$ & Rim \\
\hline Z9 & $0.000 \pm 0.000$ & $0.473 \pm 0.022$ & $\mathrm{Y}$ & $\operatorname{Rim}$ \\
\hline Z10 & $0.037 \pm 0.004$ & $0.396 \pm 0.004$ & $\mathrm{Y}$ & Rim \\
\hline K1 & $0.044 \pm 0.003$ & $3.033 \pm 0.054$ & $\mathrm{~N}$ & Body \\
\hline $\mathrm{K} 2$ & $0.042 \pm 0.001$ & $6.567 \pm 0.206$ & Near & Body \\
\hline K3 & $0.043 \pm 0.001$ & $7.767 \pm 0.206$ & Near & $\operatorname{Rim}$ \\
\hline K4 & $0.097 \pm 0.003$ & $6.600 \pm 0.289$ & Near & $\operatorname{Rim}$ \\
\hline K5 & $0.053 \pm 0.001$ & $6.000 \pm 0.205$ & $\mathrm{~N}$ & Body \\
\hline K6 & $0.056 \pm 0.003$ & $6.600 \pm 0.000$ & $\mathrm{~N}$ & Body \\
\hline $\mathrm{K} 7$ & $0.027 \pm 0.003$ & $4.167 \pm 0.094$ & $\mathrm{Y}$ & Rim \\
\hline K8 & $0.079 \pm 0.003$ & $1_{5} 9.233 \pm 0.020$ & $\mathrm{Y}$ & Body \\
\hline K9 & $0.019 \pm 0.001$ & $5.333 \pm 0.076$ & $\mathrm{Y}$ & $\operatorname{Rim}$ \\
\hline
\end{tabular}

Table 1: Total chloride recovered from all samples by both distilled water and with an ammonium fluoride solution. 